\title{
Commentary: Always do right
}

\author{
Kenji Minatoya, $\mathrm{MD}, \mathrm{PhD}$
}

\footnotetext{
From the Department of Cardiovascular Surgery, Graduate School of Medicine, Kyoto University, Kyoto, Japan. Disclosures: Author has nothing to disclose with regard to commercial support.

Received for publication March 15, 2019; accepted for publication March 15, 2019; available ahead of print May $21,2019$.

Address for reprints: Kenji Minatoya, MD, PhD, Department of Cardiovascular Surgery, Graduate School of Medicine, Kyoto University, 54 Kawaharacho, Shogoin, Sakyo-ku, Kyoto 6068507, Japan (E-mail: minatoya@kuhp.kyoto-u.ac.jp).

J Thorac Cardiovasc Surg 2020;159:779-80

$0022-5223 / \$ 36.00$

Copyright (C) 2019 by The American Association for Thoracic Surgery

https://doi.org/10.1016/j.jtcvs.2019.03.101
}

Open aortic arch repair has become safer in the last 3 decades because of the improvement in its strategy and materials, as well as the advent of studies regarding brain protection and temperature setting during the repair. However, the cannulation strategy to establish cardiopulmonary bypass remains a critical issue to safely perform the operation. ${ }^{1,2}$ The presence of atherosclerotic lesions in patients undergoing arch repair is associated with an increased risk of embolisms induced by aortic cannulation.

In this issue of the Journal, Kim and colleagues ${ }^{3}$ report the efficacy of right axillary artery cannulation for arch repair in reducing embolic stroke incidence and mortality rates. I congratulate their fine clinical research and superb surgical results with arch repair. Their report's main point is that the use of right axillary cannulation led to lower embolic stroke incidence and mortality rate.

The data of the enrolled patients were retrospectively collected over decade, and the aortic pathology included both acute type A dissection and atherosclerotic aneurysm. The axillary cannulation group included sole axillary cannulation and some combination with peripheral cannulation, whereas the nonaxillary cannulation group consisted of femoral artery and ascending aortic cannulation. In addition, several different strategies regarding cerebral perfusion were performed during the study period. Therefore, the mortality and morbidity rates, even after propensity score matching, may be influenced by several factors that were not superficially visible. I think that the variable trends of the cannulation strategy and the rate of stroke incidence and mortality in the report revealed the difficulty of the analysis.

Although the axillary artery may be a peripheral artery, the axillary artery cannulation is categorized as a central cannulation. Particularly, it is because this artery connects to the supra-aortic branches. Their report consequently confirmed that the incidence rate of right-hemisphere stroke was significantly lower in the right axillary artery cannulation group. Numata and colleagues ${ }^{4}$ reported that the right subclavian artery cannulation was cerebroprotective with

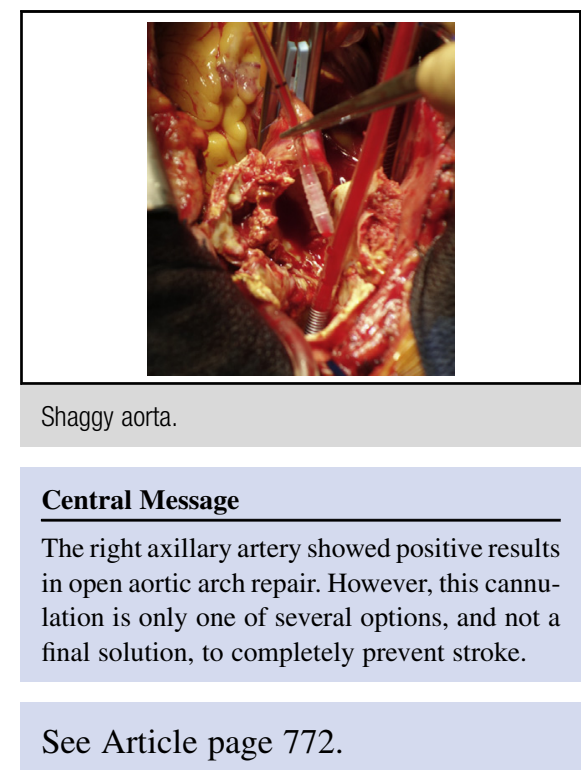

the use of computational fluid dynamics simulation. They showed that a retrograde flow of the brachiocephalic artery and an antegrade flow of the right common carotid artery were produced from the blood streamline from the right subclavian artery throughout the cardiac cycle. In addition, they indicated that the blood flow from the right subclavian artery cannula and aortic valve perfused the left-side supraaortic branches. Accordingly, they concluded that the right subclavian artery cannulation was cerebroprotective, especially on the right hemisphere. In other words, the flow from the right subclavian artery could have the sandblasting effect on the inside of the aortic arch and lead to left-side stroke. To completely prevent stroke due to the arterial cannulation, an isolation technique should be considered. ${ }^{5}$ The severely atherosclerotic aorta, so-called shaggy aorta, should be treated using this technique. ${ }^{6}$ In their report, the right axillary artery showed positive results. However, it is necessary to note that this cannulation is only one of the several options, and not a final solution, to completely prevent stroke.

\section{References}

1. Benedetto U, Raja SG, Amrani M, Pepper JR, Zeinah M, Tonelli E, et al. The impact of arterial cannulation strategy on operative outcomes in aortic surgery: evidence from a comprehensive meta-analysis of comparative studies on 4476 patients. J Thorac Cardiovasc Surg. 2014;148:2936-43.

2. Svensson LG, Blackstone EH, Rajeswaran J, Sabik JF III, Lytle BW, GonzalezStawinski G, et al. Does the arterial cannulation site for circulatory arrest influence stroke risk? Ann Thorac Surg. 2004;78:1274-84. 
3. Kim J-H, Lee SH, Lee S, Youn Y-N, Yoo K-J, Joo H-C. Axillary artery cannulation reduces early embolic stroke and mortality after open arch repair with circulatory arrest. J Thorac Cardiovasc Surg. 2020;159:772-8.e4.

4. Numata S, Itatani K, Kawajiri H, Yamazaki S, Kanda K, Yaku H. Computational fluid dynamics simulation of the right subclavian artery cannulation. $J$ Thorac Cardiovasc Surg. 2017:154:480-7.
5. Shiiya N, Kunihara T, Kamikubo Y, Yasuda K. Isolation technique for stroke prevention in patients with a mobile atheroma. Ann Thorac Surg. 2001;72: 1401-2.

6. Shiiya N. Aortic arch replacement for degenerative aneurysms: advances during the last decade. Gen Thorac Cardiovasc Surg. 2013; 61:191-6. 